\title{
THE PACHYTENE KARYOTYPE OF SCHIZOPHYLLUM COMMUNE ANALYZED BY THREE DIMENSIONAL RECONSTRUCTION OF SYNAPTONEMAL COMPLEXES
}

\author{
by \\ PHEYA CARMI ${ }^{1}$, PREBEN B. HOLM, YIGAL KOLTIN ${ }^{1}$, \\ SØREN W. RASMUSSEN, JEAN SAGE and DENISE ZICKLER² \\ Department of Physiology, Carlsberg Laboratory, \\ Gamle Carlsberg Vej 10, DK-2500 Copenhagen, Valby \\ (Address for reprint requests) \\ 1. Genetics Unit, George S. Wise Center for Life Sciences, Tel-Aviv University, Tel-Aviv, Israel \\ 2. Laboratorie de Génétique, Université de Paris-Sud, Centre d'Orsay, Orsay, France
}

Keywords: Recombination nodules, centromere, bivalent, chromosome number

Three dimensional reconstructions of 15 pachytene nuclei of Schizophyllum commune have revealed in each nucleus 11 distinct synaptonemal complexes, demonstrating a haploid chromosome number of 11 . Each bivalent contained one short region of condensed chromatin marking the position of the centromere. The synaptonemal complex of each bivalent contained from 0 to six recombination nodules. A high correlation was found between the total length of the synaptonemal complexes in a nucleus and the number of recombination nodules. Total synaptonemal complex length correlated only weakly with the nuclear volume. 


\section{INTRODUCTION}

Schizophyllum commune is serving as an object for studies of various genetic phenomena such as the evolution of a natural polymorphism (13), genetic regulation of morphogenesis $(18,19)$, mitotic recombination (6), and repair of UV induced damage (12). In addition, phenomena directly related to meiosis are currently studied with this organism such as the genetic control of recombination $(14,20$, 21,22 ) and the increased frequency of spontaneous mutations during meiosis (15). Recently, partial synchronization of meiosis was attained with hydroxyurea and the time of premeiotic DNA synthesis was determined (2, $3)$.

The cytological description of meiosis in Schizophyllum is based on the studies with the light microscope by EHRLICH and MCDONOUGH (5) and a study with both light and electron microscopy by RADU, STEINLAUF, and KoLTIN (17). The difficulties of cytological studies of the small nucleus in this organism are apparent from the discrepancy in the haploid chromosome numbers reported in these two studies. The earlier study (5) reported 4 chromosomes as the haploid number and the more recent study 8 chromosomes (17). An additional cytological analysis (11) described a haploid number of 4 chromosomes, and genetical studies detected 7 linkage groups (7).

Three dimensional reconstructions of synaptonemal complexes at pachytene offer the possibility to determine the chromosome number accurately in organisms where a light microscopical analysis is equivocal $(1,16)$. In addition it is possible to obtain qualitative and quantitative structural information on the processes of chromosome pairing, crossingover, and disjunction as mediated by the synaptonemal complex (for reviews see 9, 25). Recent studies of Drosophila (4), Saccharomyces (1), Sordaria (26) and Neurospora $(8,10)$ have focused on the presence of electron dense nodules, the so-called "recombination nodules" (4) in association with the central region of the synaptonemal complex. The analysis of their number and distribution have suggested a relationship between the nodules and crossingover.
The present paper reports on the three dimensional reconstruction of the synaptonemal complexes in 15 pachytene nuclei of Schizophyllum commune. The pachytene karyotype is described using the absolute and relative lengths of the synaptonemal complexes as well as the position of the centromeric regions and the nucleolus organizer. Finally, the number and distribution of recombination nodules in the bivalents are determined.

\section{MATERIAL AND METHODS}

\subsection{Materials}

Two haploid compatible strains were used to form the fertile heterokaryon. Both strains were from the collection at Tel-A viv University. Mating of the haploid strains was performed on standard Schizophyllum solid complete medium $(23)$ at $30^{\circ} \mathrm{C}$. After incubation for 72 hours the plates were transferred to a growth chamber. Fruiting bodies were induced by exposure of the fertile heterokaryon to a daily 16 hour light period at $25^{\circ} \mathrm{C}$.

\subsection{Electron microscopy}

Mature fruiting bodies were placed in a $4 \%$ phosphate buffered $(0.06 \mathrm{M}, \mathrm{pH} 7.2)$ glutaraldehyde solution with a purification index of 0.2 and fixed for 3 hours at room temperature. After rinsing, the fruiting bodies were osmicated in a $2 \%$ phosphate buffered osmiumtetroxide solution at room temperature for 2 hours, washed twice in buffer, 4 times in distilled water and left overnight in distilled water at $4^{\circ} \mathrm{C}$. The tissue was then fixed/stained in a $2 \%$ aqueous uranyl acetate solution at $60^{\circ} \mathrm{C}$ for 3 hours. After cooling to room temperature the tissue was dehydrated in a graded alcohol series, embedded in SPURR's low viscosity resin and polymerized for 24 hours at $70^{\circ} \mathrm{C}$.

Serial sections were cut on a Reichert Om U3 ultramicrotome equipped with a diamond knife. The serial sections were picked up on single slot grids without formvar film and thereafter transferred onto grids with supporting film using a micromanipulator for 
maneuvering the grids during the transfer process. Sections were stained in a $5 \%$ aqueous uranyl acetate solution for $20 \mathrm{~min}$ at $60^{\circ} \mathrm{C}$, rinsed, and poststained in lead citrate for $15 \mathrm{~min}$. The staining was carried out in an automatic staining apparatus.

Sections were examined and selected nuclei were photographed in a Siemens Elmiscope 102 or a Siemens Elmiscope IA at a primary magnification of 15,000 or 20,000 times.

\subsection{Three dimensional reconstruction}

Three dimensional reconstructions were performed in the following way: the synaptonemal complex segments from 5-10 sections were traced onto transparent plastic film. After having encompassed the whole nucleus the tracings of all synaptonemal complex segments of each bivalent were redrawn on a new sheet of plastic film together with the relevant section numbers.

\subsection{Measurements and calculation}

The projected synaptonemal complex lengths were measured on the plastic sheets containing the entire bivalent and the absolute length calculated taking into account the thickness of the sections (estimated to be $0.08 \mu \mathrm{m}$ ) with the aid of a Hewlett Packard digitizer (HP 9864A) and calculator (HP 9825A). In order to analyse the distribution of recombination nodules on the different bivalent arms, the length of each arm of a bivalent was adjusted to the mean length of that particular bivalent arm and the relative position of the recombination nodule(s) determined for the normalized arm. These normalized bivalent arms were then divided into segments of $0.13 \mu \mathrm{m}$. The mean number of nodules per segment of each bivalent arm was calculated and used to illustrate the distribution of nodules along the synaptonemal complex.

The digitizer and computer were also used to determine the nuclear volume. The area of the nucleus was measured on every other electron micrograph. The sum of these values was multiplied by $0.16 \mu \mathrm{m}$ (two times the section thickness) and used as an estimate of the nuclear volume.

\section{RESULTS AND DISCUSSION}

\subsection{General description of the pachytene nucleus}

The ultrastructure of the pachytene nucleus and the structure and dimensions of the constituents of the synaptonemal complex has previously been described by VOLZ et al. (24) and RADU et al. (17). The present results are in agreement with the previous observations.

Survey pictures of a pachytene nucleus are shown in Figure 1 and a complete reconstruction is presented in Figure 2. The lateral components of the synaptonemal complex are anchored at the inner membrane of the nuclear envelope (Figure 3) with the attachment sites evenly distributed throughout the nuclear envelope. As illustrated in Figure 2 the synaptonemal complex is frequently twisted $180^{\circ}$ and occasionally bends abruptly within a short distance (bivalents 6, 7, 8, and 9 in Figure 2). Each bivalent has been found to possess a single $200 \mathrm{~nm}$ long region of condensed chromatin (Figure 4). Such local regions of condensed chromatin have not been found in the reconstructed nuclei of Sordaria (26) or Neurospora $(8,10)$ whereas similar regions of condensed chromatin have been found to mark the centromeric region of zygotene and early pachytene bivalents in human spermatocytes (HOLM and RASMUSSEN, unpublished observations). That these regions in Schizophyllum likewise identify the position of the centromere is supported by their constant location, if the same bivalent is compared in different nuclei.

Each nucleus contains one nucleolus which is organized by a region on the distal half of the short arm of an almost metacentric bivalent. The synaptonemal complex of this region is surrounded by condensed chromatin to which the nucleolus is associated (Figure 1). The condensed chromatin extends to the telomere of the short arm (Figure 2).

The central component of the synaptonemal complex of the majority of bivalents contain one or more electron dense nodules. The nodules are slightly ovoid with diameters of 30$50 \mathrm{~nm}$ and 70-100 nm (Figure 5a). In cross section the nodules appear circular (Figure 5b).

A single highly electron dense centrosome is regularly present in an indentation of the nuclear envelope (Figure 6). 

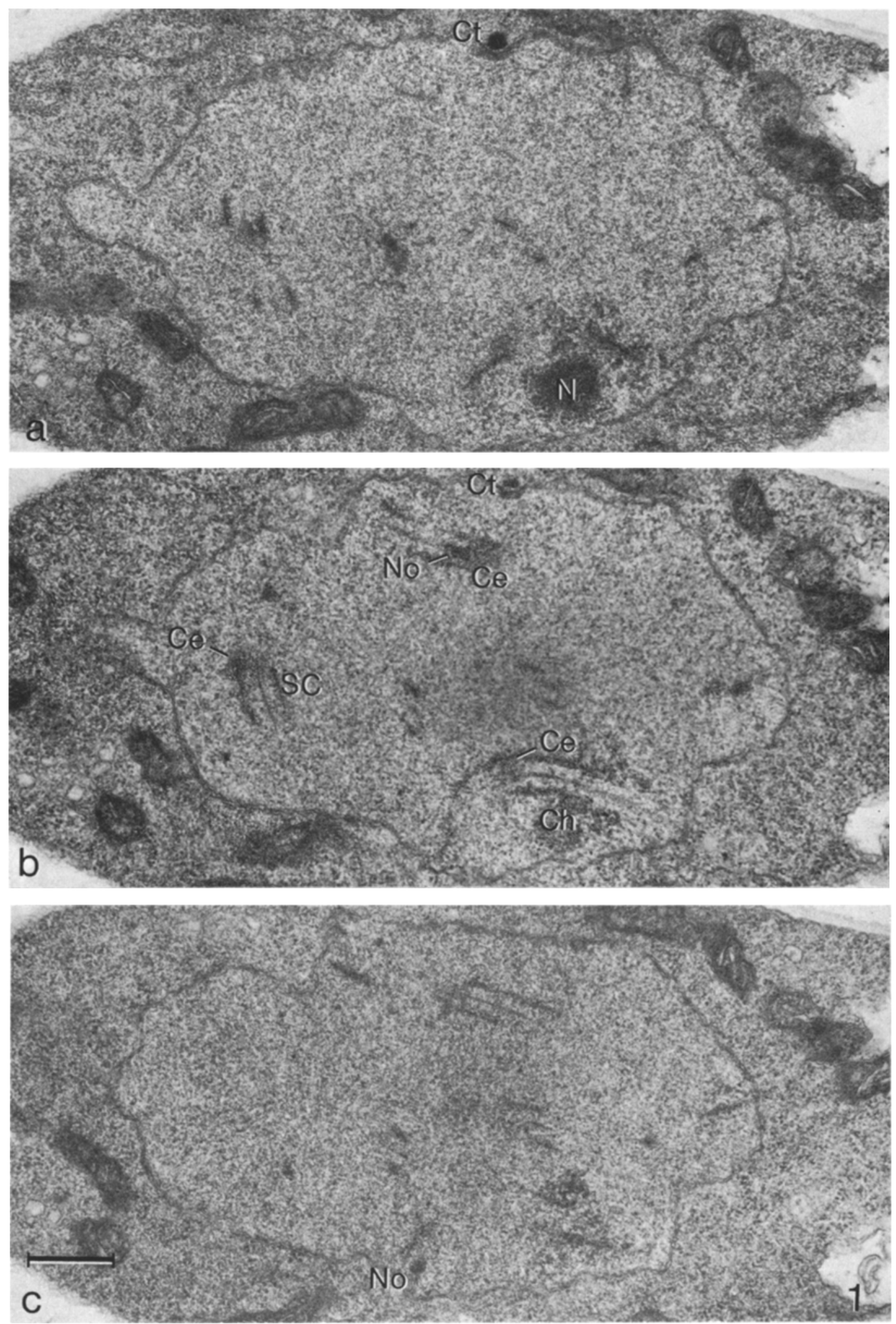
Figure 1. Three consecutive sections through a pachytene nucleus showing several synaptonemal complexes, including the nucleolus organizing bivalent (bivalent 10 ). The distal half of the short arm is surrounded by condensed chromatin $(\mathrm{Ch})$ which is associated with the nucleolus $(\mathrm{N})$. The centromeric chromatin $(\mathrm{Ce})$ of bivalent 10 can be observed in Figure $\mathrm{lb}$ and a recombination nodule (No) is seen near the telomere in Figure Ic. A recombination nodule is located close to the centromeric chromatin of another bivalent in Figure $1 \mathrm{~b}$. The centrosome $(\mathrm{Ct})$ is closely associated with the nuclear envelope, Figures $1 \mathrm{a}, \mathrm{b} .(\mathrm{Bar}=0.5 \mu \mathrm{m})$

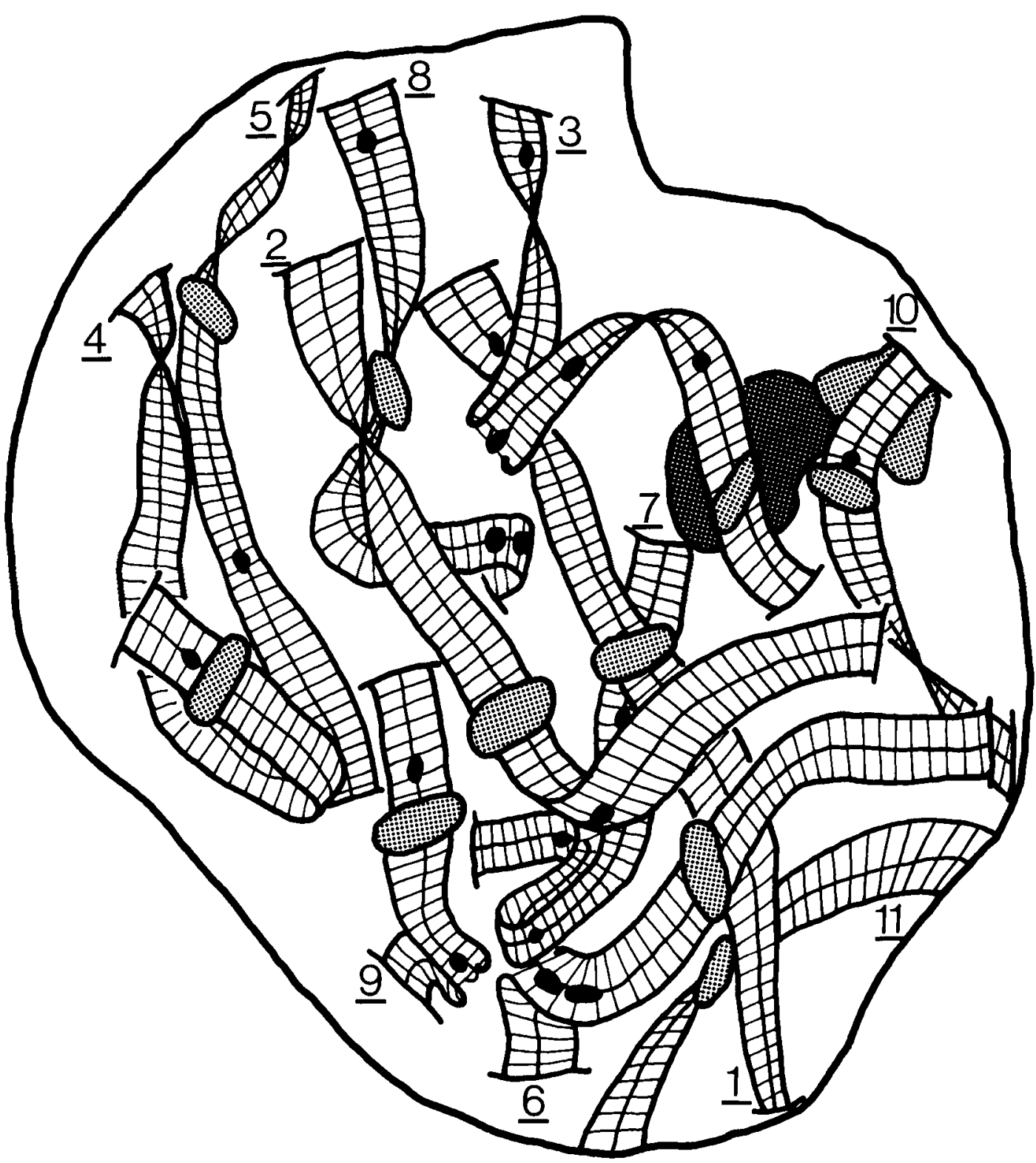

Figure 2. A complete reconstruction of a pachytene nucleus (number E6). All 22 chromosomes are paired into bivalents each with a continuous synaptonemal complex from telomere to telomere. All telomeres are attached to the nuclear envelope. The nucleolus organizer region extends to the telomere of bivalent 10 and is associated with a nucleolus (dark hatching). The centromeric regions of the bivalents are denoted by a lighter hatching. Note the recombination nodules in the central region of the synaptonemal complexes. The underlined numbers are the bivalent numbers. 


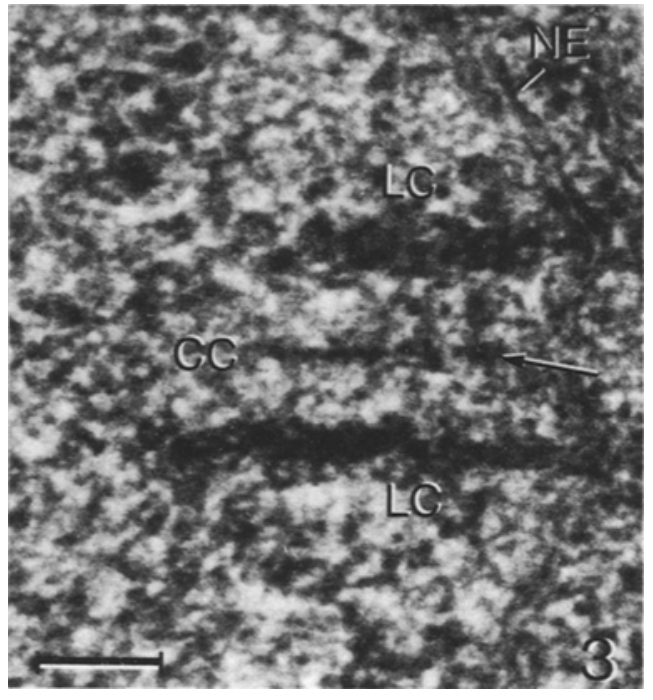

Figure 3. The attachment site of a synaptonemal complex to the nuclear envelope. The lateral components (LC) are anchored at the inner membrane of the nuclear envelope (NE). The central component (CC) terminates $50 \mathrm{~nm}$ from the nuclear envelope (arrow). (Bar $=0.1 \mu \mathrm{m})$

\subsection{Chromosome number}

The three dimensional reconstruction of 15 pachytene nuclei has revealed in each nucleus 11 distinct synaptonemal complexes representing 22 chromosomes homologously paired into bivalents (Figures 2, 7). This is in contrast to earlier reports of 4 to 8 bivalents per nucleus $(5,17,11)$. Ten of the bivalents ( numbers 1-9 and 11) are attached to the nuclear envelope at both ends (Figure 2). Bivalent 10 is attached to the nuclear envelope at one end. The nucleolus organizer region (Figure 1,2 ) near the telomere of the other arm makes it difficult to establish whether also this telomere is attached or ends inside the condensed chromatin of the nucleolus organizer region.

\subsection{Classification of bivalents}

On the basis of absolute and relative lengths of the synaptonemal complex, the position of the centromeric region expressed as the centromere index (length of the short arm $x$ 100 /length of the entire bivalent), and the position of the nucleolus organizer region, it is possible to establish a set of criteria by which the 11 bivalents can be classified (Figure 7):

\section{Group A 1: The longest metacentric \\ 2: The second longest metacentric}

Group B 3: The longest submetacentric

4: The second longest submetacentric

Group C 5: The longest submetacentric of the remaining bivalents

6: The longest metacentric of the remaining bivalents

7: More submetacentric than 8

8: More metacentric than 7

9: The shortest submetacentric

Group D 10: The bivalent carrying the nucleolus organizer region

11: The shortest metacentric

It should be emphasized that only bivalent 10 with the nucleolus organizer region can be identified unequivocally. The numbers assigned to the remaining bivalents may in some cases represent different bivalents in different nuclei. Taking bivalent 1 and 2 as an example, the two bivalents have almost the same length (2.8 $\mu \mathrm{m}$ and $2.6 \mu \mathrm{m}$, Table $\mathrm{l}$ ) thus making a classification beyond an assignment to group $\mathrm{A}$ ambiguous. Furthermore, both bivalents are metacentric (centromere indices of 47 and 46) which also introduces ambiquity in the identification of the two arms of each bivalent. The difficulty is illustrated by bivalent 10 where the two arms can be distinguished from one another by the presence of the nucleolus organizer region. In eleven nuclei the arm with the organizer region was the shorter one; whereas in four nuclei the arm with the organizer region was the longer one of the bivalent.

In general, the classification at the level of groups (A-D) can be expected to be correct in the majority of nuclei, whereas an additional classification within each group is less reliable. 

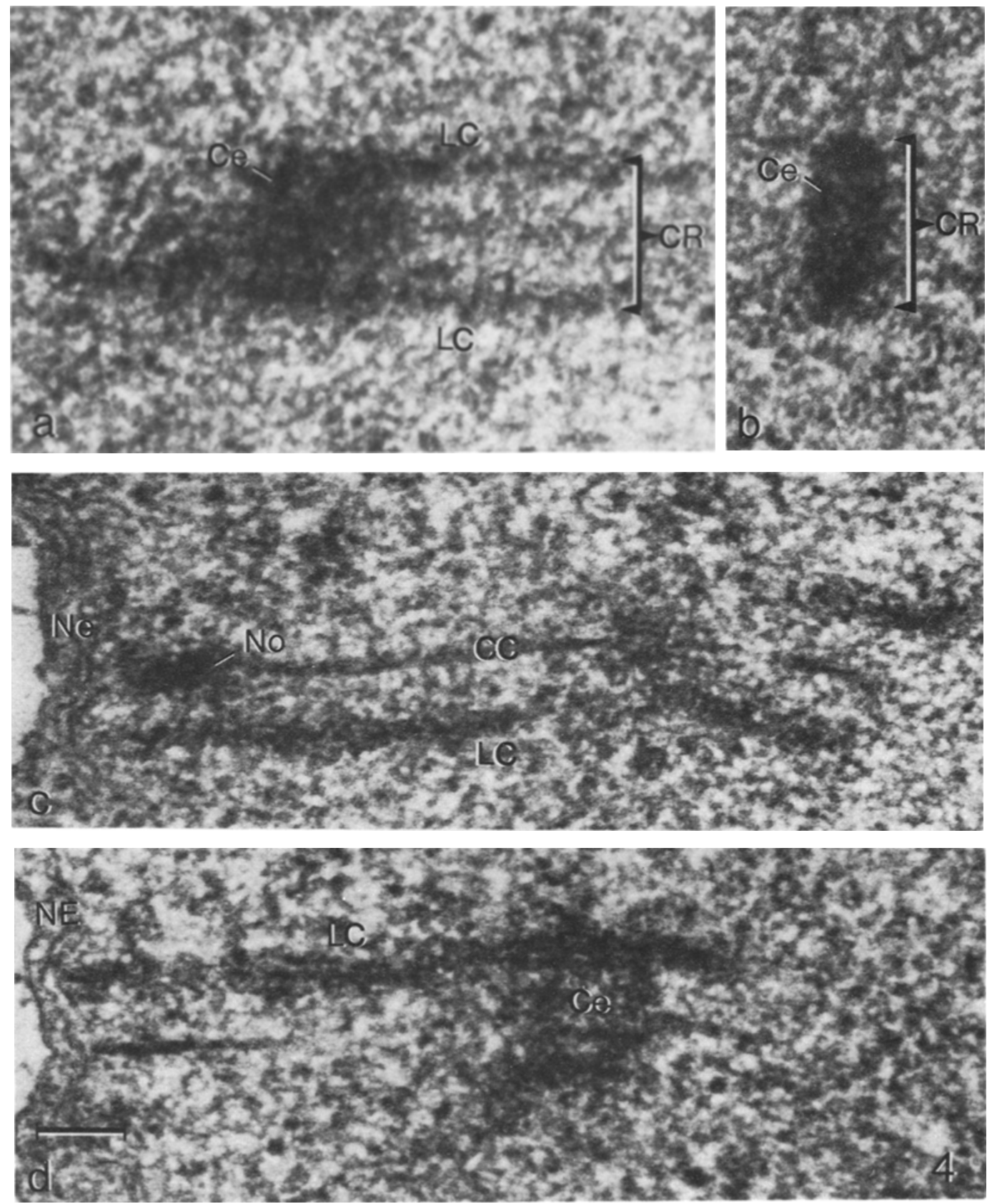

Figure 4. The ultrastructure of the centromeric chromatin is shown in longitudinal (Figure 4a) and cross section (Figure $4 \mathrm{~b}$ ) of the synaptonemal complex. The central region (CR) is filled with condensed chromatin between the lateral components (LC). Two consecutive sections of a pachytene bivalent and its centromeric chromatin (Ce) is illustrated in Figures $4 c$, d. A recombination nodule (No) is seen in the central region (CR) close to the attachment site of the synaptonemal complex. NE, nuclear envelope. CC, central component. LC, lateral component. $(\mathrm{Bar}=0.1 \mu \mathrm{m})$ 

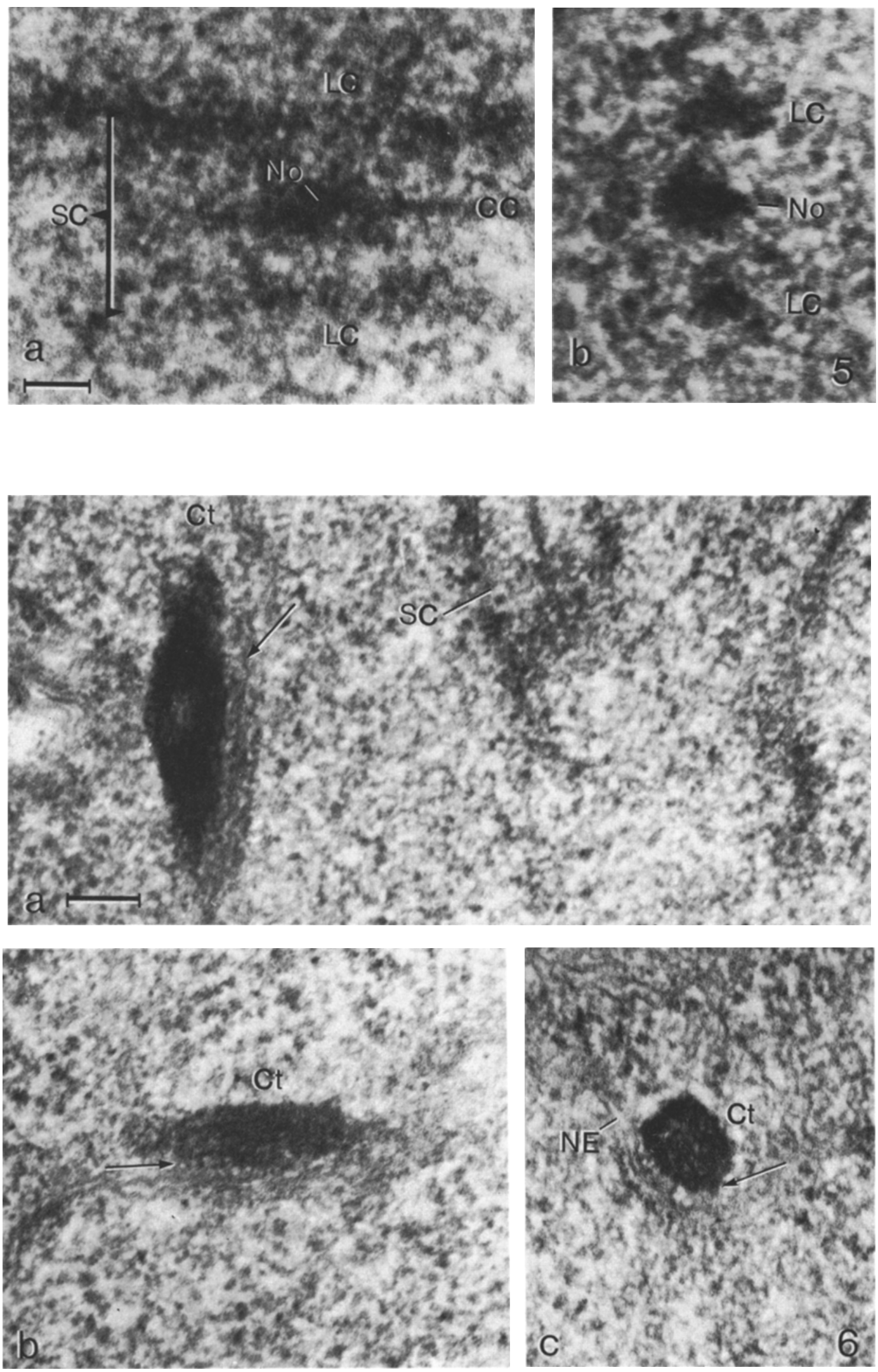
Figure 5. High magnification of a longitudinal (Figure 5a) and a cross section (Figure 5b) of a synaptonemal complex with a recombination nodule. The recombination nodule (No) is associated with the central component (CC) of the synaptonemal complex (SC) and consists of coarse fibers with an electron density similar to that of the lateral components (LC). In cross section the nodule is positioned slightly lateral to the plane defined by the two lateral components. $(\mathrm{Bar}=0.05 \mu \mathrm{m})$

Figure 6. High magnification of the centrosome in longitudinal sections (Figures 6a, b) and cross section (Figure 6c). The elliptical centrosome ( $\mathrm{Ct}$ ) is associated with the nuclear envelope (NE) by fine fibers (arrows). Aiternating electron dense and electron transparent regions suggesting a tubular substructure of the centrosome can be observed in Figures 6b, c. SC, synaptonemal complex. $($ Bar $=0.1 \mu \mathrm{m})$

\subsection{Synaptonemal complex length}

It is evident from Table II that the length of the entire synaptonemal complex complement varies considerably between different nuclei, the shortest complement being $14.9 \mu \mathrm{m}$ and the longest $35.4 \mu \mathrm{m}$. The mean synaptonemal complex length of the 15 nuclei is $23.3 \mu \mathrm{m}$ corresponding to $0.4 \%$ of the DNA length $(6.1$ $\mathrm{mm}$ ) at the $2 \mathrm{C}$ level (11). It is possible on the basis of electron density of the centromeric region to divide the 15 nuclei into two groups: one consisting of 6 nuclei with less distinct centromeric region and one including 9 nuclei with distinct, electron scattering centromeric regions (Table II). The total complement length for the first group is $28.6 \mu \mathrm{m}$ while the second group has a mean complement length of 19.5 $\mu \mathrm{m}$. This difference is significant as judged by a

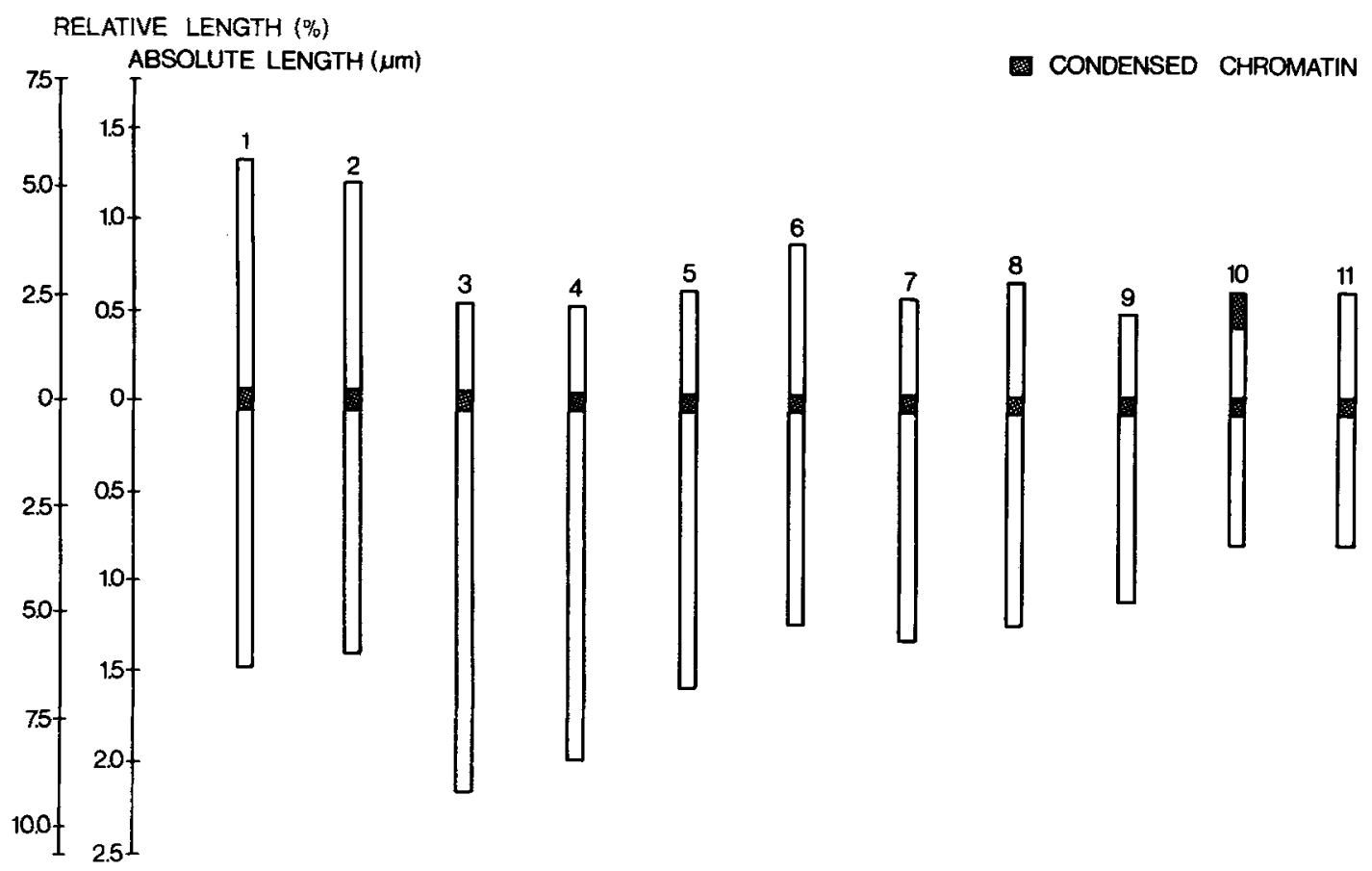

Figure 7. Idiogram showing the absolute lengths and relative lengths of the synaptonemal complexes of the 11 bivalents of Schizophyllum commune. Note the distal hatched region on bivalent 10 which marks the position of the nucleolus organizing region. 


\section{Table I}

Absolute length, relative length, centromere index, and number of recombination nodules for each of the 11 bivalents. The data are the mean values and standard deviation from 15 nuclei.

\begin{tabular}{|c|c|c|c|c|}
\hline $\begin{array}{l}\text { Chromosome } \\
\text { number }\end{array}$ & $\begin{array}{c}\text { Absolute } \\
\text { length }(\mu \mathrm{m})\end{array}$ & $\begin{array}{l}\text { Relative length } \\
\text { (\% of total) }\end{array}$ & $\begin{array}{l}\text { Centromere } \\
\text { index }\end{array}$ & $\begin{array}{l}\text { Number of } \\
\text { recombination } \\
\text { nodules }\end{array}$ \\
\hline 1 & $2.8 \pm 0.7$ & $12.1 \pm 0.8$ & $47 \pm 2$ & $1.3 \pm 1.0$ \\
\hline 2 & $2.6 \pm 0.7$ & $11.0 \pm 0.8$ & $46 \pm 4$ & $1.4 \pm 0.6$ \\
\hline 3 & $2.8 \pm 0.7$ & $12.2 \pm 1.0$ & $20 \pm 6$ & $2.1 \pm 1.3$ \\
\hline 4 & $2.5 \pm 0.6$ & $10.8 \pm 0.8$ & $21 \pm 8$ & $1.6 \pm 0.7$ \\
\hline 5 & $2.2 \pm 0.5$ & $9.3 \pm 0.7$ & $28 \pm 7$ & $1.4 \pm 0.8$ \\
\hline 6 & $2.1 \pm 0.5$ & $9.1 \pm 0.6$ & $41 \pm 6$ & $1.8 \pm 1.1$ \\
\hline 7 & $1.9 \pm 0.6$ & $8.3 \pm 0.7$ & $30 \pm 5$ & $1.7 \pm 1.2$ \\
\hline 8 & $1.9 \pm 0.7$ & $8.0 \pm 0.7$ & $35 \pm 6$ & $1.1 \pm 0.8$ \\
\hline 9 & $1.6 \pm 0.4$ & $6.8 \pm 0.6$ & $31 \pm 7$ & $1.2 \pm 0.7$ \\
\hline 10 & $1.4 \pm 0.3$ & $6.3 \pm 0.9$ & $44 \pm 8$ & $1.0 \pm 0.8$ \\
\hline 11 & $1.4 \pm 0.4$ & $6.0 \pm 0.8$ & $44 \pm 6$ & $1.3 \pm 0.6$ \\
\hline
\end{tabular}

Table II

Nuclear volume, total synaptonemal complex length, and total number of recombination nodules for 15 pachytene nuclei of Schizophyllum commune.

\begin{tabular}{|c|c|c|c|}
\hline $\begin{array}{l}\text { Nucleus } \\
\text { number }\end{array}$ & $\begin{array}{c}\text { Nuclear } \\
\text { volume } \\
\left(\mu \mathrm{m}^{3}\right)\end{array}$ & $\begin{array}{c}\text { Total } \\
\text { synaptonemal } \\
\text { complex } \\
\text { length }(\mu \mathrm{m})\end{array}$ & $\begin{array}{c}\text { Total } \\
\text { number of } \\
\text { recombination } \\
\text { nodules }\end{array}$ \\
\hline E6 & 7.6 & 26.0 & 19 \\
\hline E10 & 9.5 & 30.0 & 24 \\
\hline NI & 10.5 & 25.7 & 18 \\
\hline N3 & 11.3 & 35.4 & 31 \\
\hline N5 & 12.0 & 26.9 & 24 \\
\hline $\mathrm{Al}$ & 6.0 & 27.6 & 13 \\
\hline Mean & $9.5 \pm 2.3$ & $28.6 \pm 3.7$ & $22 \pm 6$ \\
\hline $\mathrm{E} 2$ & 7.3 & 19.2 & 15 \\
\hline E3 & 4.7 & 19.3 & 11 \\
\hline E4 & 8.1 & 23.2 & 16 \\
\hline E5 & 7.2 & 14.9 & 8 \\
\hline E7 & 7.2 & 17.2 & 13 \\
\hline E9 & 8.4 & 18.7 & 10 \\
\hline N4 & 9.1 & 24.6 & 18 \\
\hline $\mathrm{A} 2$ & 5.5 & 18.5 & 11 \\
\hline A3 & 7.0 & 20.1 & 11 \\
\hline Mean & $7.2 \pm 1.4$ & $19.5 \pm 2.9$ & $13 \pm 3$ \\
\hline $\begin{array}{l}\text { Mean of all } \\
\text { nuclei }\end{array}$ & $8.1 \pm 2.1$ & $23.2 \pm 5.6$ & $16 \pm 6$ \\
\hline
\end{tabular}


t-test $(\mathbf{P}<0.001)$. At zygotene, a morphologically distinguishable centromere region could not be identified unequivocally in the majority of the bivalents. Therefore, if one assumes a progressive increase in condensation of the centromeric chromatin from zygotene into pachytene, it is likely that the nuclei belonging to the first group are in early pachytene and those in the second group in mid to late pachytene. Due to the limited number of nuclei which have been analyzed and to the fact that measurement of synaptonemal complex lengths and/or lateral component lengths at zygotene are lacking, group one may include other pachytene stages as well as early pachytene.

A comparison between the total synaptonemal complex length and nuclear volume as illustrated in Figure 8 and in Table II indicates a low correlation between these two nuclear parameters. The smallest nucleus $(4.7$ $\mu \mathrm{m}^{3}$ ) has a total complement length of $19.3 \mu \mathrm{m}$ whereas the largest nucleus $\left(12.0 \mu \mathrm{m}^{3}\right)$ has a total complement length of $26.9 \mu \mathrm{m}$, i.e. a 2.5 times difference in volume corresponds to a 1.4 times difference in complement length. Taking the nucleus with the lowest complement length
$(14.9 \mu \mathrm{m})$ and that with the largest complement length $(35.4 \mu \mathrm{m})$ as a second example the difference in volume is 1.6 times $\left(7.2 \mu \mathrm{m}^{3}\right.$ for the smallest nucleus and $11.3 \mu \mathrm{m}^{3}$ for the largest) and the corresponding difference in complement length is 2.4 times.

\subsection{Recombination nodules (number per nucleus)}

The total number of recombination nodules per nucleus (Table II) varies considerably among the 15 nuclei, the lowest number being 8 and the highest number 31 . The mean value for all 15 nuclei is $16 \pm 6$. A comparison between the number of recombination nodules and the total length of the synaptonemal complex complement shows a high correlation (correlation coefficient $=0.90$ ) between these two parameters (Figure 9). It is also evident from the data in Table II that when the two groups of nuclei are considered separately the first group has the highest number of nodules (mean number $=22$ ) as compared to the second, probably more advanced group (mean number $=13$ ). As judged by a t-test this difference is significant ( $P$ $<0.05$ ).
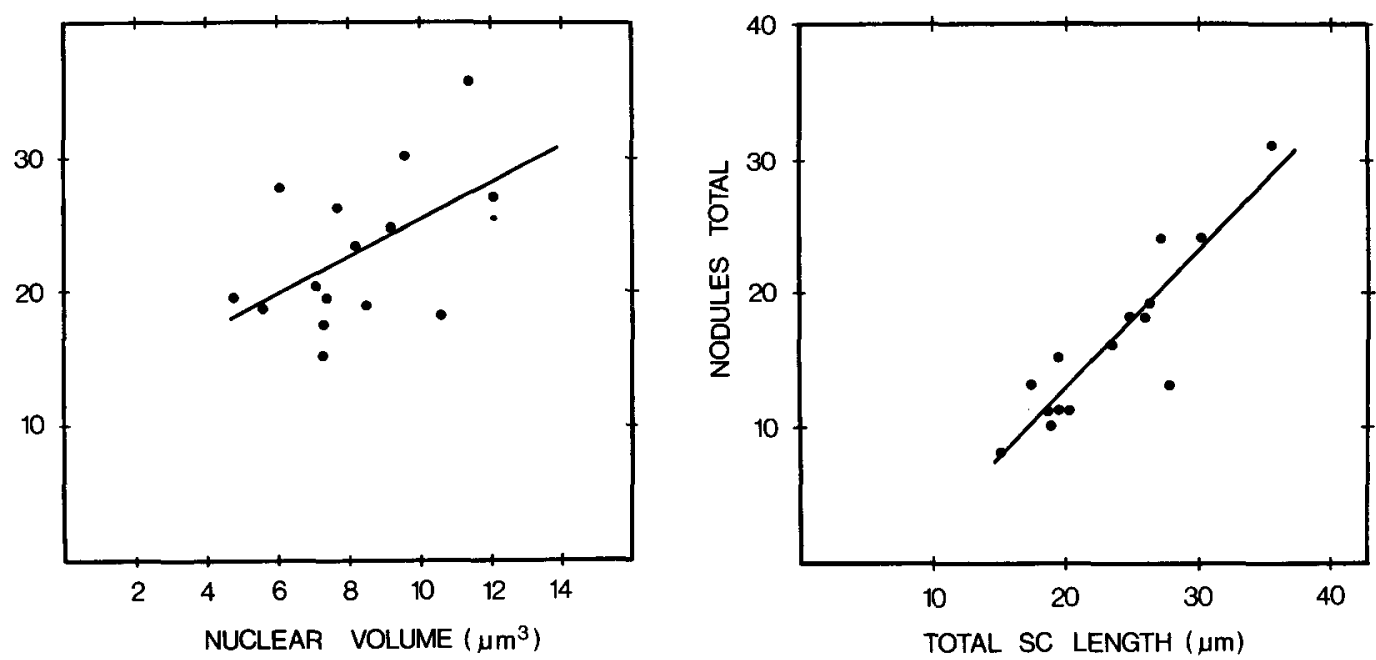

Figure 8. A comparison between nuclear volume and total length of the synaptonemal complex (SC) complement for each of the 15 nuclei. The correlation coefficient is 0.51 .

Figure 9. A comparison of total length of the synaptonemal complex (SC) complement and the total number of recombination nodules for each of the 15 nuclei. The correlation coefficient is 0.90 . 

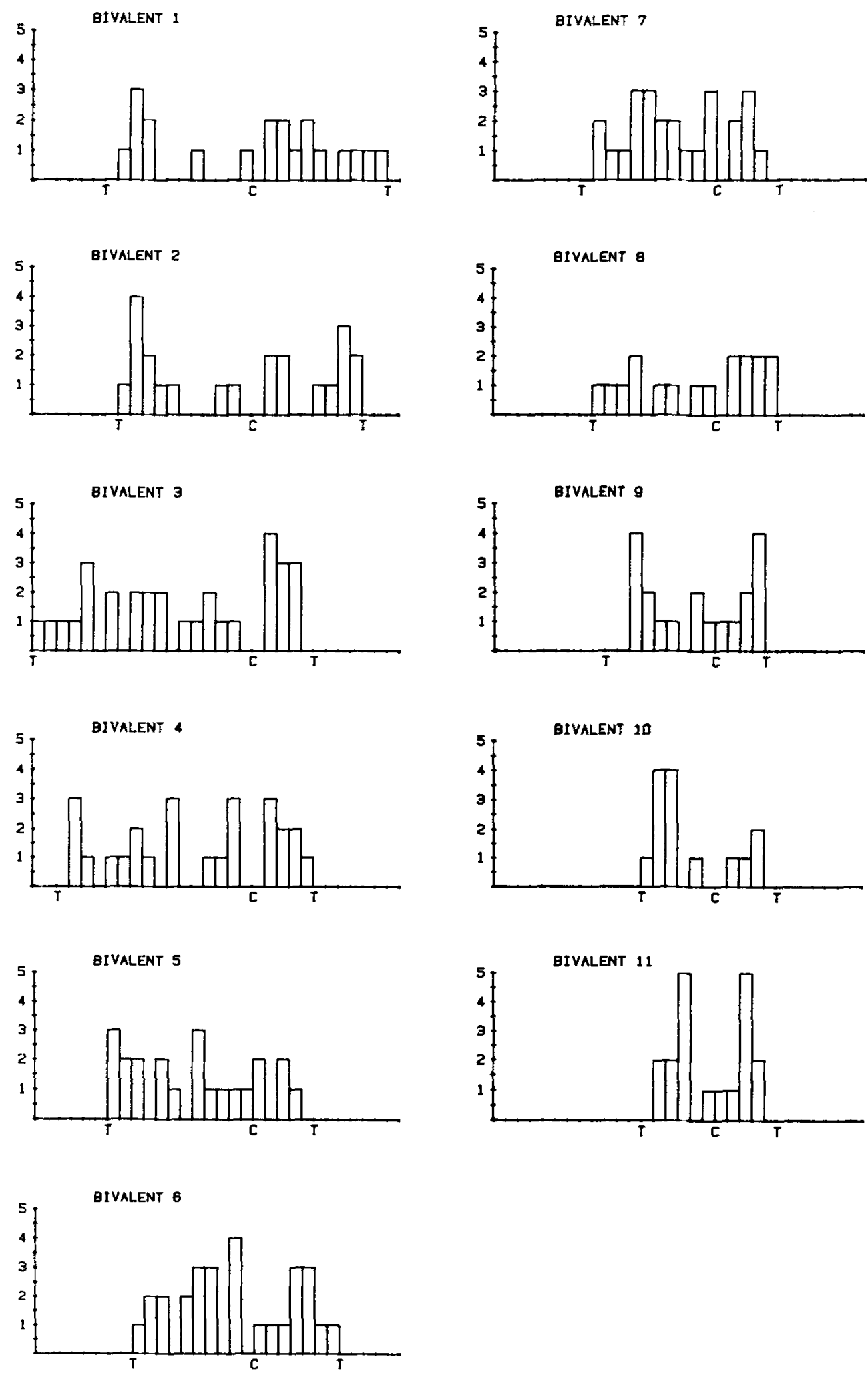

Figure 10. The distribution of recombination nodules in each of the 11 bivalents after normalization of individual bivalent arms to their mean length. The length of the segments on the abscissa is $0.13 \mu \mathrm{m}$ in all histograms. The

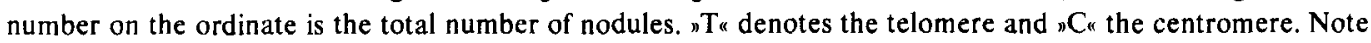
that in some bivalents, e.g. 2,3,4, and 10, nodules are lacking in the segments on either side of the centromere. 


\subsection{Recombination nodules (bivalent 10)}

As mentioned previously (section 3.3.) only bivalent 10 could be unequivocally identified in all 15 nuclei. The analysis of the distribution of recombination nodules after normalization of the individual arms of bivalent 10 shows (Figure 10) that 8 out of 10 nodules are located within the two segments in the middle of the long arm (1.2 $\mu \mathrm{m}$ synaptonemal complex per nodule). In the arm which carries the nucleolus organizer region only 4 recombination nodules were identified in the 15 nuclei $(2.3 \mu \mathrm{m}$ synaptonemal complex per nodule). The two arms have approximately the same length $(0.8 \mu \mathrm{m}$ and 0.6 $\mu \mathrm{m}$ respectively). It is likely that this difference in the frequency of nodules in the two arms can be ascribed to the presence of the nucleolus organizer region in one of them.

\subsection{Recombination nodules (bivalents 1-9 and 11)}

The illustrations of the distribution of the recombination nodules presented in Figures 10 and 12 as well as in Table III are based on the assumption that the classification of bivalents according to the criteria given in section 3.3. is correct in the majority of the nuclei and that those bivalents which are incorrectly ranked do not alter the picture of the distribution of the nodules. From one to six recombination nodules were found in each of 151 bivalents. In the remaining 14 bivalents recombination nodules were not identified (Table IV). As seen in this table a complete lack of recombination nodules is prevalent among the shorter bivalents. Table III and Figure 12 show a clear difference in synaptonemal complex length per nodule between the longer and the shorter bivalents. Taking bivalents 1 and 11 as examples the long bivalent 1 has one nodule per $2.2 \mu \mathrm{m}$ of synaptonemal complex while the short bivalent 11 has one nodule per $1.1 \mu \mathrm{m}$ complex. A similar difference in synaptonemal complex length per nodule is observed when the two arms of a bivalent are compared (Figure 11 and Table III). In the long arm recombination

Table IV

Bivalents without recombination nodules.

\begin{tabular}{cc}
\hline Nucleus number & Bivalent number \\
\hline E6 & 11 \\
A1 & 5,6 \\
\hline E2 & 10 \\
E3 & 10 \\
E5 & $8,9,10$ \\
E9 & 1,9 \\
A2 & 8 \\
A3 & 5,6 \\
\hline
\end{tabular}

Table III

Synaptonemal complex lengths per recombination nodule for the long and short arms of the 11 bivalents. Mean values from 15 nuclei.

\begin{tabular}{cccc}
\hline $\begin{array}{c}\text { Bivalent } \\
\text { number }\end{array}$ & \multicolumn{3}{c}{ Synaptonemal complex $(\mu \mathrm{m})$ per recombination nodule } \\
Short arm & Total \\
\hline 1 & 2.8 & 1.6 & 2.2 \\
2 & 1.9 & 1.6 & 1.9 \\
3 & 1.6 & 0.9 & 1.3 \\
4 & 1.7 & 0.9 & 1.6 \\
5 & 1.3 & 1.8 & 1.6 \\
6 & 1.1 & 1.2 & 1.2 \\
7 & 1.1 & 1.5 & 1.1 \\
8 & 2.2 & 1.3 & 1.7 \\
9 & 1.5 & 0.9 & 1.3 \\
10 & 1.2 & 2.3 & 1.4 \\
11 & 1.2 & 1.0 & 1.1 \\
\hline
\end{tabular}



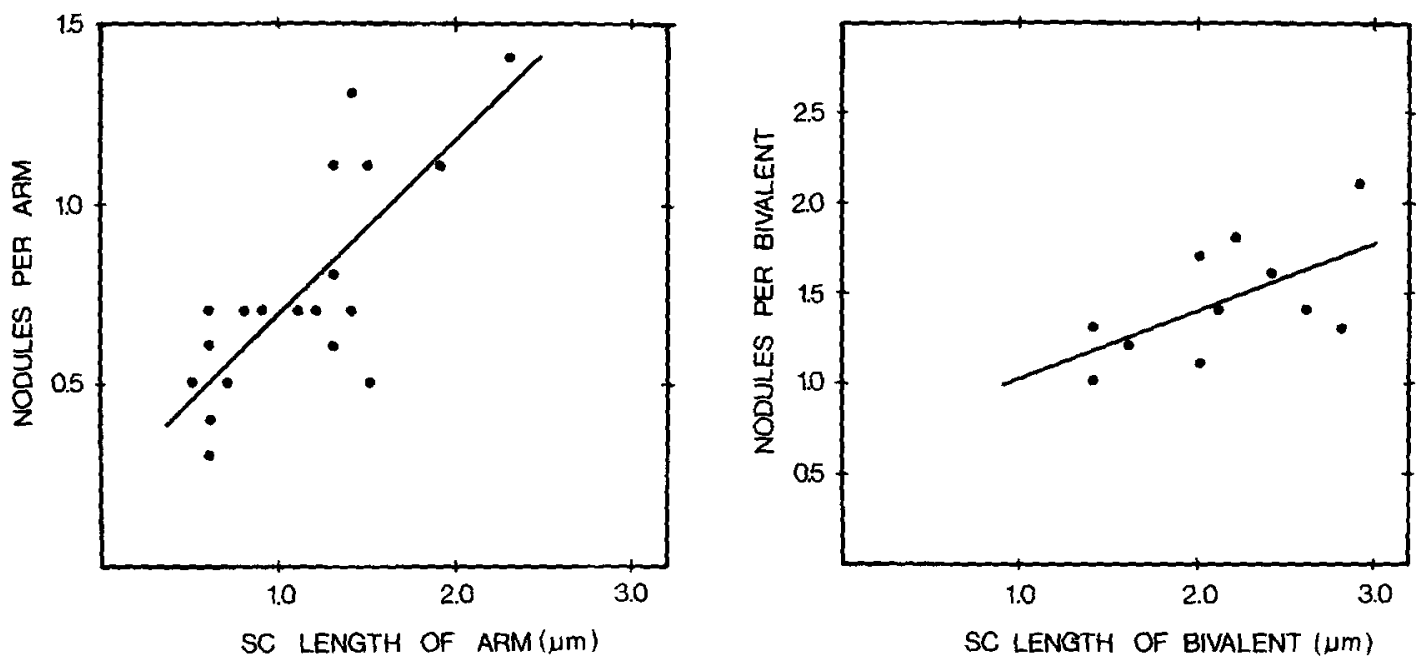

Figure 11. A comparison between the mean length of the synaptonemal complex of each bivalent arm and the mean number of recombination nodules in that arm. The correlation coefficient is 0.78 .

Figure 12. A comparison between the mean length of the synaptonemal complex of each bivalent and the mean number of recombination nodules in that bivalent. The correlation coefficient is 0.60 .

nodules are found with a frequency of one nodule per $1.6 \mu \mathrm{m}$ synaptonemal complex whereas the mean frequency for the short arms is one nodule per $1.4 \mu \mathrm{m}$ complex. This effect is even more pronounced when the figures for individual bivalents are considered (e.g., bivalents 1, 3, 4, 8 and 9, Table III).

As seen in Figure 10, nodules appear frequently to be absent, or present in low numbers in segments on either side of the centromeric region. Evidence for a low frequency of nodules around the centromeres in Neurospota has been found by Gillies (10). Segments close to the telomeres of pachytene bivalents with a high frequency of nodules as reported by ZlCKLER (26) in Sordaria are not evident in Schizophyllum.

A correlation between the distribution of nodules and either chiasmata or frequencies of crossing-over cannot yet be established due to insufficient information on these parameters in Schizophyllum. Because of the small number of nuclei studied and the ambiguity in the classification of the bivalents a statistical analysis of the distribution of recombination nodules is not warranted.

\section{CONCLUSIONS}

1. At pachytene 11 synaptonemal complexes can be traced in each nucleus, demonstrating a haploid chromosome number of 11 .

2. With the exception of bivalent 10 which can be identified in all nuclei by the nucleolus organizing region, a classification of the individual bivalents beyond a coarse grouping is ambiguous.

3. The total length of the synaptonemal complex complement varies between $14.9 \mu \mathrm{m}$ and $35.4 \mu \mathrm{m}$ with a mean value of $23.2 \mu \mathrm{m}$. This variation does not appear to be correlated with variation in nuclear volume. A subdivision of the 15 nuclei into two groups on the basis of the condensation of the centromeric chromatin reveals significant differences in synaptonemal complex length between the two groups, one group having a mean value of $28.6 \mu \mathrm{m}$ whereas the mean value for the second group is $19.5 \mu \mathrm{m}$.

4. The mean number of recombination nodules for all nuclei is 16 . The total number of nodules per nucleus shows a high correlation with the total length of the synaptonemal complex complement. The two substages of pachytene exhibit a significant difference in mean number of 
nodules per nucleus, the first group having a higher number than the second.

5. The position of recombination nodules is not constant when the same bivalent is analyzed in different nuclei.

6. Recombination nodules appear to be absent or present in low amount in the vicinity of the centromeric regions of many bivalents.

\section{ACKNOWLEDGEMENTS}

It is a great pleasure to thank ANNSOFI STEINHOLTZ and NiNA RASMUSSEN for their skilled technical assistance during the course of this study. We also wish to thank professor D. VON WETTSTEIN for his valuable criticism of the manuscript. The work was supported by grant GM-22051 of the National Institutes of Health, USPHS to professor D. VON WETTSTEIN.

\section{REFERENCES}

1. Beyers, B. \& L. GOETSCH: Electron microscopic observations on the meiotic karyotype of diploid and tetraploid Saccharomyces cerevisiae. Proc. Nat. Acad. Sci. USA 72, 5056-5060 (1975)

2. Carmi, P., M. Raudaskoski, J. Stamberg \& Y. Koltin: Meiosis in Schizophyllum commune: The effect of hydroxyurea on basidiospore sporulation, germination and nuclear number. Molec. Gen. Genetics 158, 17-21 (1978)

3. Carmi, P., Y. Koltin \& J. Stamberg: Meiosis in Schizophyllum commune: Premeiotic DNA replication and meiotic synchrony induced with hydroxyurea. Genet. Res. (in press) (1978)

4. Carpenter, A. T. C.: Electron microscopy of meiosis in Drosophila melanogaster females II. The recombination nodule - a recombination associated structure at pachytene? Proc. Nat. Acad. Sci. USA 72, 3186-3189 (1975)

5. Ehrlich, H. G. \& E. S. McDonough: The nuclear history in the basida and basidiospores of Schizophyllum commune (Fries) Amer. J. Bot. 36, 360-363 (1949)

6. Frankel, C. \& A. H. Ellingboe: Sexual incompatability factors and somatic recombination in Schizophyllum commune. Genetics 85, 427 437 (1977)

7. Frankel, C. \& A. H. Ellingboe: New mutations and a 7 chromosome linkage map of Schizophyllum commune. Genetics 85, 417-427 (1977)
8. Gillies, C. B.: Reconstruction of the Neurospora crassa pachytene karyotype from serial sections of synaptinemal complexes. Chromosoma (Berl.) 36, 119-130 (1972)

9. Gillies, C. B.: Synaptonemal complex and chromosome structure. Ann. Rev. Genet. 9, 91109 (1975)

10. GiLlies, C. B.: The relationship between synaptonemal complexes, recombination nodules and crossing-over in Neurospora crassa bivalents and translocation quadrivalents. Genetics (in press) (1978)

11. Haapala, O. K. \& I. Nienstedt: Chromosome ultrastructure in the basidiomycete fungus Schizophyllum commune. Hereditas $84,49-60$ (1976)

12. Hundert, P., Y. Koltin \& J. Stamberg: Repair of UV induced damage in Schizophyllum commune. Mut. Res. (in press) (1978)

13. Koltin, Y., J. Stamberg \& P. A. Lemke: Genetic structure and evolution of the incompatability factors in higher fungi. Bacteriol. Rev. 36, 156171 (1972)

14. Koltin, Y. \& J. Stamberg: Genetic control of recombination in Schizophyllum commune: Location of a gene controlling $B$ factor recombination. Genetics 74, 55-62 (1973)

15. Koltin, Y.,J. Stamberg \& R. Ronen: Meiosis as a source of spontaneous mutations in Schizophyllum commune. Mut. Res. 27, 319-325 (1975)

16. Moens, P. B. \& F. O. Perkins: Chromosome number of a small protist: accurate determination. Science 166, 1289-1293 (1969)

17. Radu, M., R. Steinlauf \& Y. Koltin: Meiosis in Schizophyllum commune: Chromosomal behaviour and the synaptinemal complex. Arch. Microbiol. 98, 301-310 (1974)

18. RAPER, J. R.: Genetics of sexuality in high fungi. Ronald Press, New York. (1966)

19. RAPER, C. A. \& J. R. RAPER: Mutational analysis of a regulatory gene for morphogenesis in Schizophyllum. Proc. Nat. Acad. Sci. USA 70, 1427-1431 (1973)

20. Simchen, G. \& J. Stamberg: Fine and coarse controls of genetic recombination. Nature 222, 329-332 (1969)

21. Simchen, G. \& J. Stamberg: Genetic control of recombination in Schizophyllum commune: Specific and independent regulation of adjacent and non-adjacent chromosome regions. Heredity 247, 369-381 (1969)

22. Stamberg, J. \& Y. Koltin: Genetic control of recombination in Schizophyllum commune: Evidence for a new type of regulatory site. Genetical Res. 22, 101-111(1973) 
P. CARm et al.: The pachytene karyotype of Schizophyllum

23. Stevens, R. B.: Mycology Guidebook. University of Washington Press, Seattle 703 pp. (1974)

24. Volz, P. A., C. Heintz, R. Jersild \& D. J. Niederpruem: Synaptinemal complexes in Schizophyllum commune. J. Bacteriol. 95, 14761477 (1968)

25. WestergaArd, M. \& D. von Wettstein: The synaptinemal complex. Ann. Rev. Genet. 6, 71$111(1972)$
26. ZICKLER, D.: Development of the synaptonemal complex and the wrecombination nodule during meiotic prophase in the seven different bivalents of the fungus Sordaria macrospora (Auersw.). Chromosoma (Berl.) 61, 289-316 (1977) 